Article

\title{
Two-Step Production of Neofructo-Oligosaccharides Using Immobilized Heterologous Aspergillus terreus 1F-Fructosyltransferase Expressed in Kluyveromyces lactis and Native Xanthophyllomyces dendrorhous $\mathrm{G}^{6}$-Fructosyltransferase
}

\author{
Jan Philipp Burghardt ${ }^{1,2}$, Markus Baas ${ }^{1}$, Doreen Gerlach ${ }^{3}$ and Peter Czermak ${ }^{1,2,3, *(D)}$ \\ 1 Institute of Bioprocess Engineering and Pharmaceutical Technology, \\ University of Applied Sciences Mittelhessen, 35390 Giessen, Germany \\ 2 Faculty of Biology and Chemistry, Justus-Liebig University of Giessen, 35390 Giessen, Germany \\ 3 Fraunhofer Institute for Molecular Biology and Applied Ecology (IME), Project Group Bioresources, \\ Heinrich-Buff-Ring 26, 35392 Giessen, Germany \\ * Correspondence: peter.czermak@lcb.chemie.uni-giessen.de; Tel.: +49-641-309-2551
}

Received: 10 July 2019; Accepted: 5 August 2019; Published: 7 August 2019

\begin{abstract}
Fructo-oligosaccharides (FOS) are prebiotic low-calorie sweeteners that are synthesized by the transfer of fructose units from sucrose by enzymes known as fructosyltransferases. If these enzymes generate $\beta-(2,6)$ glycosidic bonds, the resulting oligosaccharides belong to the neoseries (neoFOS). Here, we characterized the properties of three different fructosyltransferases using a design of experiments approach based on response surface methodology with a D-optimal design. The reaction time, $\mathrm{pH}$, temperature, and substrate concentration were used as parameters to predict three responses: The total enzyme activity, the concentration of neoFOS and the neoFOS yield relative to the initial concentration of sucrose. We also conducted immobilization studies to establish a cascade reaction for neoFOS production with two different fructosyltransferases, achieving a total FOS yield of $47.02 \pm 3.02 \%$. The resulting FOS mixture included $53.07 \pm 1.66 \mathrm{mM}$ neonystose (neo-GF ${ }_{3}$ ) and $20.8 \pm 1.91 \mathrm{mM}$ neo-GF 4 .
\end{abstract}

Keywords: neofructo-oligosaccharides; prebiotic nutrition; fructosyltransferase; Lifetech ECR8285; Kluyveromyces lactis; Xanthophyllomyces dendrorhous

\section{Introduction}

Functional oligosaccharides possess health-promoting [1] and prebiotic properties [2]. The best known functional oligosaccharides are the fructo-oligosaccharides (FOS), galacto-oligosaccharides (GOS), isomalto-oligosaccharides (IMOS) and xylo-oligosaccharides (XOS) [1-3]. These diverse molecules differ in terms of their basic structure, the monosaccharides used for elongation and the chain length, resulting in a range of physicochemical and biological characteristics [1,2]. FOS are short-chain fructans, mainly consisting of fructose units, with a low calorific value [4-8]. Their prebiotic effects reflect their ability to stimulate the growth of beneficial bifidobacteria and lactobacilli while inhibiting undesirable bacteria such as Clostridium perfringens [9-12]. The sensorial qualities of FOS are similar to sucrose, but they do not promote dental caries. The sweetness varies according to the specific FOS molecule: For example, kestose, nystose and fructofuranosylnystose possess $31 \%, 22 \%$ and $16 \%$ of the sweetness of a 10\% sucrose solution, respectively [13]. Accordingly, FOS are mainly used as sugar substitutes $[14,15]$, but their thickening properties and similar filling capacity to sucrose also make them popular food additives [13]. 
FOS are classified according to the type of glycosidic bond between the glucose unit and the adjacent fructose or between subsequent fructose residues (Figure 1). If $\beta(2,1)$ glycosidic bonds are present they are classified as linear inulins, if $\beta(2,6)$ glycosidic bonds are present they are linear levans, and if both $\beta(2,6)$ and $\beta(2,1)$ glycosidic bonds are present along with $\beta(2,1)$ glycosidic extensions, they are assigned to the neoseries (neoFOS). The latter is characterized by greater thermal and chemical stability than commercially available inulins [16]. Furthermore, neokestose is the primary FOS utilized by bifidobacteria [10], which promote health by stimulating the immune system, promoting the regeneration of the intestinal flora after antibiotic therapy [17] and inhibiting bacterial pathogens by secreting growth-inhibiting substances and acids [18].

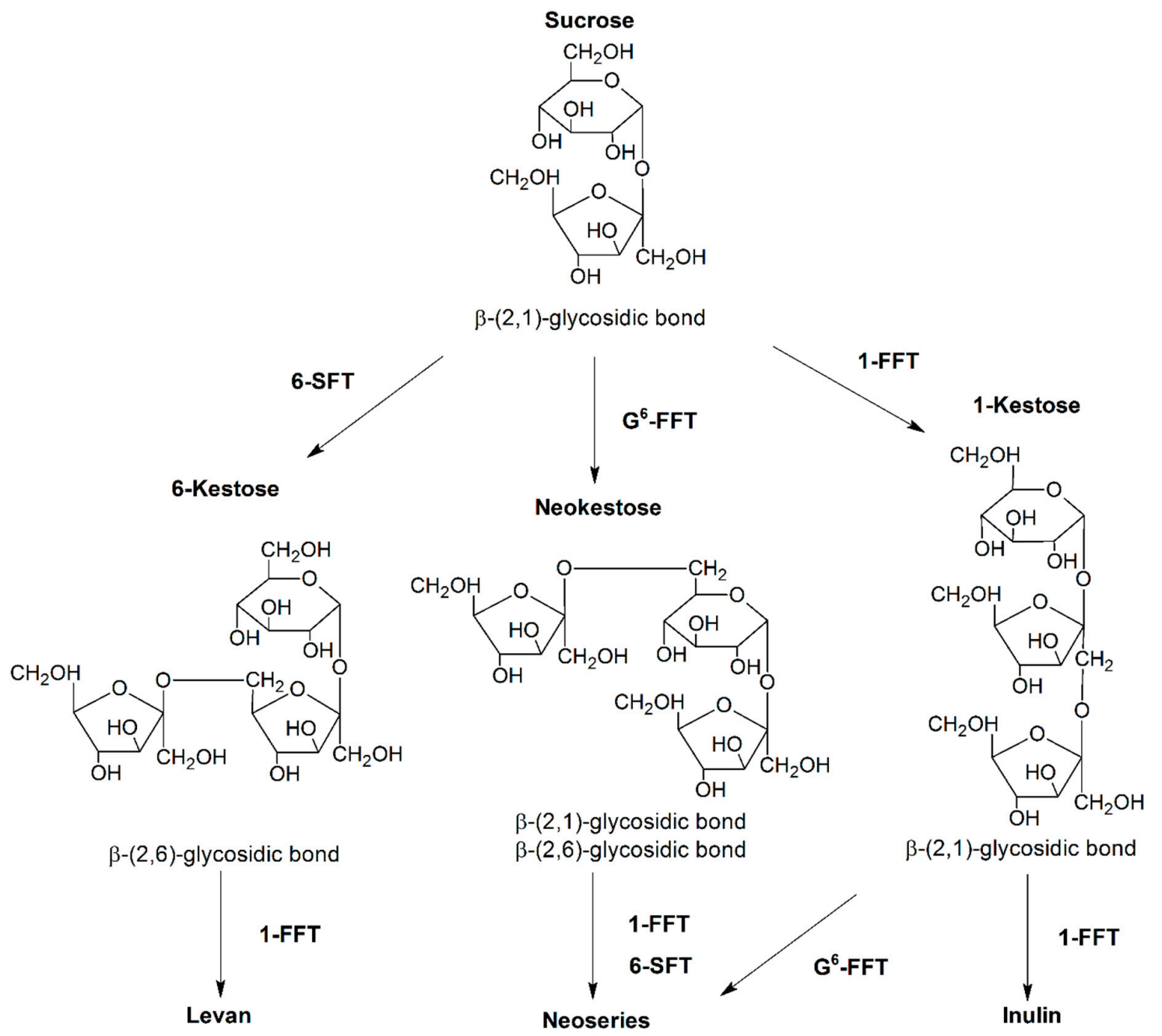

Figure 1. The Fructo-oligosaccharides (FOS) synthesis pathways starting from sucrose. $\mathrm{G}^{6}$-FFT = $\mathrm{G}_{6}$-fructosyltransferase; 1-FFT = 1-fructosyltransferase; 6-SFT = sucrose:fructan-6-fructosyltransferase.

The proposed reaction mechanism for the synthesis of neoFOS is shown in Figure 2 [19]. Sucrose is elongated by the addition of a $\beta(2,6)$-linked fructose to the glucose moiety by $\mathrm{G}^{6}$-fructosyltransferase $\left(G^{6}\right.$-FFT) to form neokestose, which is then extended by the addition of a further $\beta(2,1)$-linked fructose by 1 -fructosyltransferase (1-FFT) to form neonystose. A sucrose concentration of $600-850 \mathrm{~g} \mathrm{~L}^{-1}$ is required for this two-step reaction, and the optimal transfructosylation activity of various fructosyltransferases occurs at $50-60^{\circ} \mathrm{C}$ [13] resulting in FOS yields of up to $60 \%$ of total reaction products [20]. 


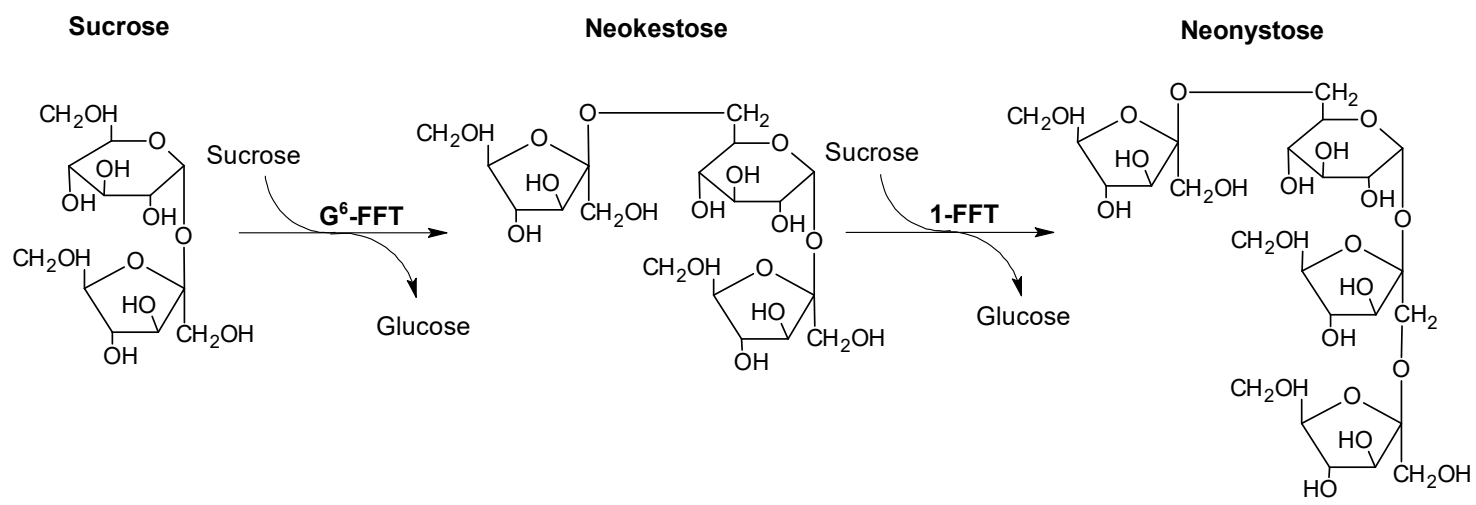

Figure 2. The neoFOS synthesis pathway starting from sucrose. $G^{6}$-fructosyltransferase $\left(\mathrm{G}^{6}\right.$-FFT) catalyzes the addition of $\beta(2,6)$-linked fructose to the glucose moiety to form neokestose, and 1-fructosyltransferase (1-FFT) adds a further $\beta(2,1)$-linked fructose to form neonystose.

One challenge with the synthesis of FOS is the inhibition of fructosyltransferases by glucose, which accumulates as a by-product [21]. This can potentially be addressed by including a second enzyme to remove the glucose. For example, glucose isomerases (E.C. 5.3.1.5) are D-xylose-ketol-isomerases that convert glucose into fructose, which also reduces of the glycemic index of the solution. The glucose isomerase from Streptomyces murinus is suitable for industrial applications because it is neither mutagenic nor teratogenic [22] and is widely used for the production of high-fructose sugar syrup [23]. Optimal isomerase activity occurs in the presence of $1 \mathrm{M}$ glucose and $5 \mathrm{mM} \mathrm{Mg}^{2+}$ as a cofactor, at a temperature of $60^{\circ} \mathrm{C}$ and a $\mathrm{pH}$ of 7.5 [24].

The efficiency of enzyme-driven reactions can be improved if the enzyme is immobilized because this allows the enzyme to be separated from the product without dedicated purification steps; multiple batch reaction cycles or continuous reactions can be carried out using the same enzyme preparation, and there is the potential to immobilize several enzymes for reaction cascades [25]. Immobilization is particularly beneficial if the enzyme costs are high because such costs can be spread over multiple reactions [26]. Even though a purified enzyme solution can enhance the immobilization yield compared to a bulk-solution, a further purification step is considered to be relevant with regard to time and costs [27]. Moreover, immobilization techniques on a carrier should be used as a simple unit operation, whereas a highly pure enzyme preparation is often not commercially available or not necessary for low-cost products, even when using whole cells to catalyze reactions [28-30]. Enzyme immobilization was first achieved by adsorbing an invertase onto aluminum hydroxide and charcoal [31], but alternatives to adsorption include entrapment, covalent binding and cross-linking [25,32]. Carrier surfaces are often modified to display aldehyde, amine or thiol groups to facilitate enzyme binding while retaining catalytic activity, thus maximizing the product yield [33]. Absorptive chromatography membranes can also be used, as reported with native $\beta$-galactosidase from Kluyveromyces lactis, for the production of GOS in a continuous membrane reactor system [34].

In this study, we propose a new cascade reaction to add value to common inulin type FOS utilizing crude enzyme solutions without chromatographic purification to enable low cost food FOS mixture. Therefore, three enzymes were characterized using a design-of-experiments approach in order to increase the yield of FOS. We varied four parameters that affect enzyme activity ( $\mathrm{pH}$, temperature, substrate concentration and reaction time) and determined their effect on the FOS concentration and yield. The focus was on 1-FFT as a model catalysis. A cascade reaction was conducted according to the neoFOS synthesis pathway to increase the value of 1-FFT catalysis products in terms of the degree of oligomerization and increasing the variety of different FOS types in one solution. We also investigated different carriers for immobilization, focusing on industrially relevant epoxy resins. Ultimately, our objective was to achieve proof of concept for a two-step neoFOS production process at the 100-mL scale, using immobilized enzymes. 


\section{Results and Discussion}

\subsection{FOS Production by Native and Recombinant Fructosyltransferases}

Fructosyltransferases synthesize FOS by hydrolyzing sucrose into glucose and fructose, then transferring the fructose to an intact sucrose molecule or an existing FOS. The type and location of the glycosidic bond determine the form of the resulting FOS molecule. Aspergillus terreus 1-FFT expressed in K. lactis primarily catalyzes the formation of $\beta(2,1)$ glycosidic bonds, resulting in the production of inulin-type FOS as the main product, along with neokestose and 6-kestose as byproducts (Figure 3). The qualification of 6-kestose was achieved using a standard kindly provided by Miguel Alcalde Galeote and Francisco J. Plou (Institute of Catalysis and Petrochemistry, Spanish National Research Council, Spain) because no commercial standards are available for neoFOS. Neokestose was assigned to the peak immediately behind 1-kestose due to the single product peak after catalysis using the native $G^{6}$-FFT produced in Xanthophyllomyces dendrorhous $[19,35]$. The main products of $\mathrm{G}^{6}$-FFT were previously shown to be neokestose and neonystose, the latter in the context of high enzyme activity $[19,36]$.

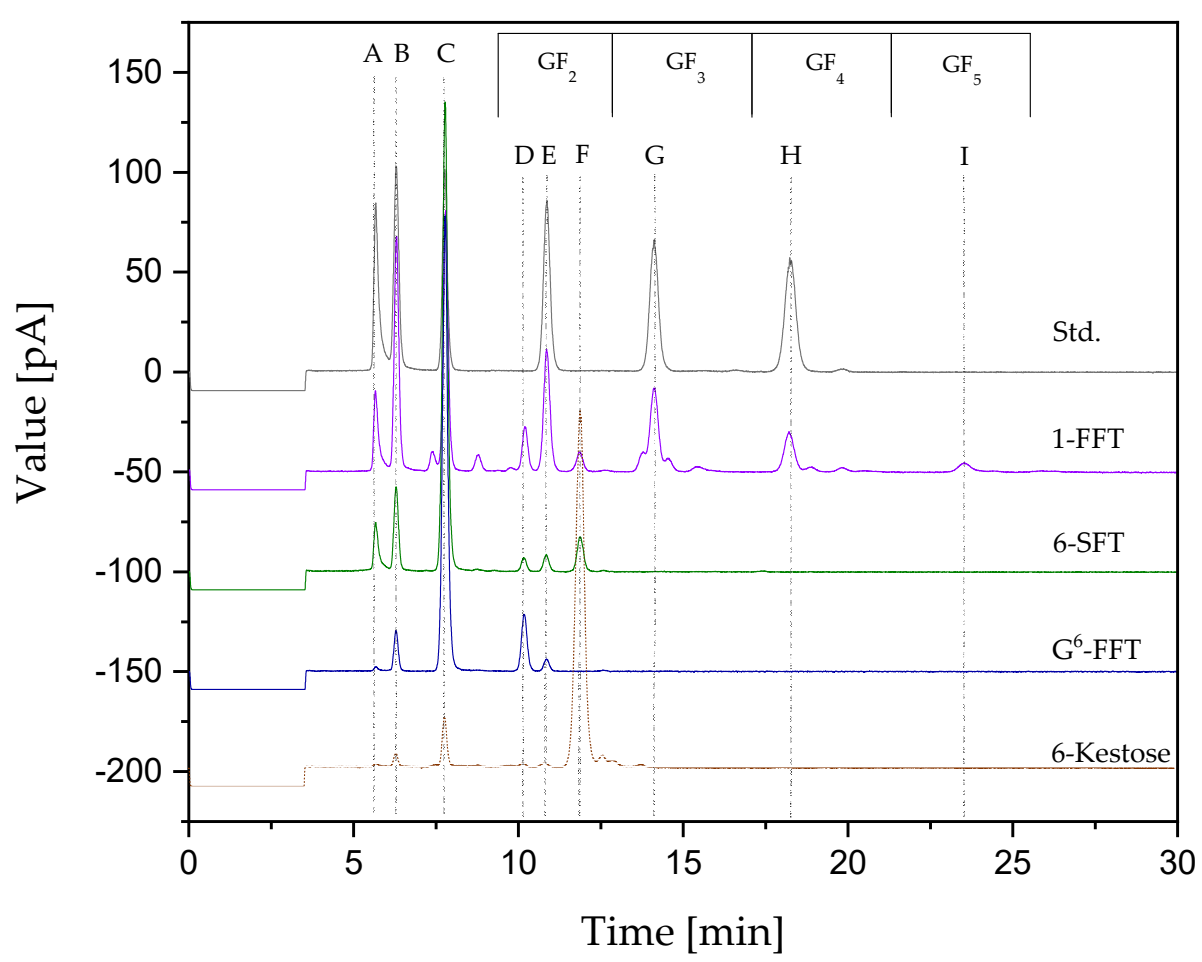

Figure 3. Chromatograms showing FOS standards and catalytic products. Offset $=50 \mathrm{pA}$ between chromatograms. The peaks correspond to (A) fructose, (B) glucose, (C) sucrose, (D) neokestose, (E) 1-kestose, (F) 6-kestose, (G) nystose, (H) 1F-fructofranosylnystose, and (I) a putative FOS with five fructose molecules $\left(\mathrm{GF}_{5}\right)$. The chromatograms represent a standard solution (Std.), the catalysis products of 1-FFT, 6-SFT and $\mathrm{G}^{6}$-FFT and a 6-kestose sample.

The native sucrose: fructan-6-fructosyltransferase (6-SFT) produced in K. lactis led to the production of neokestose, 1-kestose and primarily 6-kestose. Because 1-FFT was expressed in K. lactis, the resulting mixture of FOS represented the combined activity of native 6-SFT and recombinant 1-FFT. However, inulin-type FOS remained dominant because the strong $L A C 4$ promoter was used for 1-FFT expression [11].

The relative abundance of fructose and glucose provides an indication of the relative hydrolase and transferase activities of each enzyme because hydrolysis produces equal amounts of each monosaccharide, but only fructose is utilized during the transferase reaction. The accumulation 
of excess fructose therefore indicates a low transferase to hydrolase ratio, whereas the depletion of fructose indicates a high transferase to hydrolase ratio, the latter associated with high FOS yields. No fructose was detected among the products of $\mathrm{G}^{6}-\mathrm{FFT}$, whereas high concentrations were detected among the products of 1-FFT and 6-SFT. Accordingly, we found that $\mathrm{G}^{6}$-FFT showed almost exclusively transferase activity $(98.6 \pm 0.2 \%)$ whereas 1 -FFT showed $83.3 \pm 0.2 \%$ transferase activity and 6-SFT only $25.6 \pm 0.8 \%$ transferase activity.

\subsection{Enzyme Characterization}

In order to maximize transferase activity and thus increase the yield of FOS, it was necessary to determine reaction conditions that promoted the activity of 1-FFT and $\mathrm{G}^{6}$-FFT while minimizing the (predominantly hydrolase) activity of 6-SFT. We therefore began by determining the optimal reaction parameters for each enzyme in turn, using a design of experiments approach.

\subsubsection{Characterization of 1-FFT}

Heterologous A. terreus 1-FFT expressed in K. lactis was tested in the $\mathrm{pH}$ range 4-8 and the temperature range $40-80{ }^{\circ} \mathrm{C}$ (Figure $4 \mathrm{a}$ ) based on previous findings [11]. Similarly, an equivalent design was used to study the effect of sucrose concentration $(0.77-2.10 \mathrm{M})$ and reaction times ranging from 14 to $107 \mathrm{~min}$ (Figure 4b) [11,13].

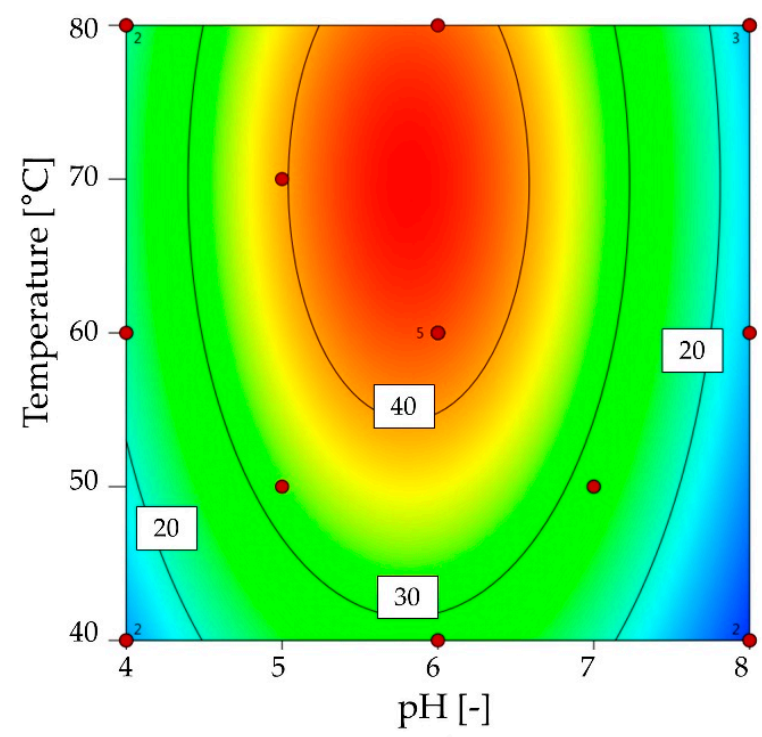

(a)

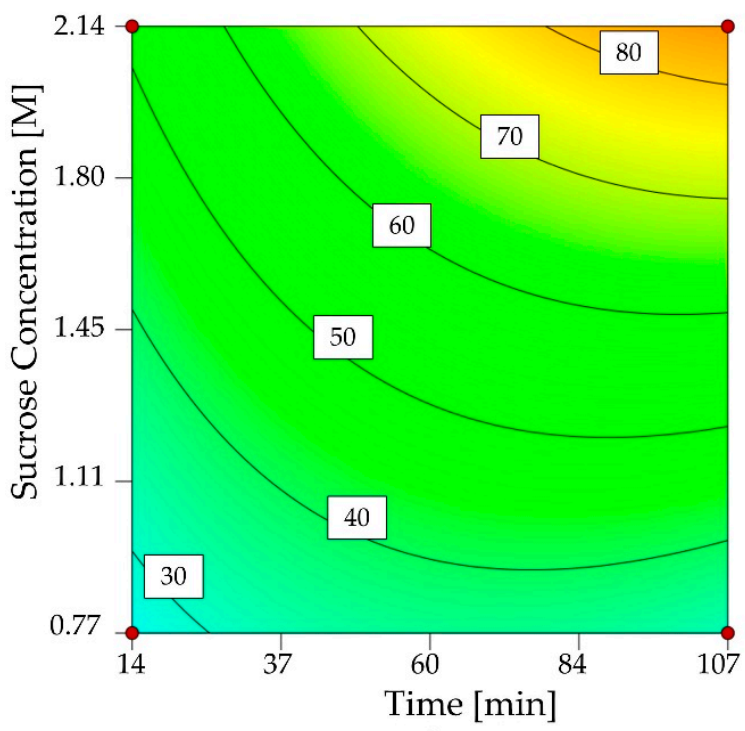

(b)

Figure 4. Contour plot of percentage FOS yield after catalysis with 1-FFT using a crude supernatant solution. (a) FOS yield as a function of $\mathrm{pH}$ and temperature ( $2 \mathrm{~h}$ reaction time, $1.75 \mathrm{M}$ sucrose). (b) FOS yield as a function of time and sucrose concentration ( $\left.\mathrm{pH} 5.8,70{ }^{\circ} \mathrm{C}\right)$.

The significant reduced quadratic model predicted a local maximum FOS yield at $\mathrm{pH} 5.8$ and $70{ }^{\circ} \mathrm{C}$. Confirmation runs $(n=4)$ were performed at the parameters that achieved the highest anticipated FOS yield within the limits of the experiment ( $\mathrm{pH} 5.8$ and $70{ }^{\circ} \mathrm{C}$ ). A FOS yield of $40.8 \pm 0.6 \%$ was achieved, which was within the $95 \%$ confidence interval of $29.7 \%-42.8 \%$. The significant reduced cubic model showed maximum FOS yields in the experimental range with increasing time and sucrose concentrations. Therefore, the confirmation runs verified the predictive power of the mathematical model under diverse conditions. 


\subsubsection{Characterization of $\mathrm{G}^{6}$-FFT}

The extracellular $\mathrm{G}^{6}$-FFT produced by X. dendrorhous has little hydrolase activity. The enzyme was characterized as above, within the $\mathrm{pH}$ range $4-7$ and the temperature range $40-70{ }^{\circ} \mathrm{C}$ based on previous findings [16,36]. Similarly, an equivalent design was used to study the effect of sucrose concentrations $(0.42-1.90 \mathrm{M})$ and reaction times ranging from 1 to $24 \mathrm{~h}$, based on previous findings and the low activity of the $\mathrm{G}^{6}$-FFT enzyme solution [19].

The significant reduced cubic model predicted FOS yields $>2.5 \%$ in the $\mathrm{pH}$ range 5.6-6.6 and the temperature range $50-56{ }^{\circ} \mathrm{C}$ (Figure 5a). In contrast to the slight decrease in FOS yields at low temperatures, catalysis at $70^{\circ} \mathrm{C}$ achieved marginal FOS yields within the tested $\mathrm{pH}$ range. Confirmation runs $(\mathrm{n}=3)$ were performed at the parameters that achieved the highest anticipated FOS yield within the limits of the experiment ( $\mathrm{pH} 6.26$ and $53^{\circ} \mathrm{C}$ ). A FOS yield of $2.50 \pm 0.07 \%$ was achieved, which was within the $95 \%$ confidence interval of $2.16 \%-3.46 \%$. In contrast to previous studies, we found that enzyme activity decreased rapidly at high temperatures and almost no activity was detected at $70{ }^{\circ} \mathrm{C}$ [36]. This may reflect the thermolability of $\mathrm{G}^{6}$-FFT and the difference in reaction time [36]. Most FOS production using $X$. dendrorhous $\mathrm{G}^{6}$-FFT is carried out under mild conditions [37].

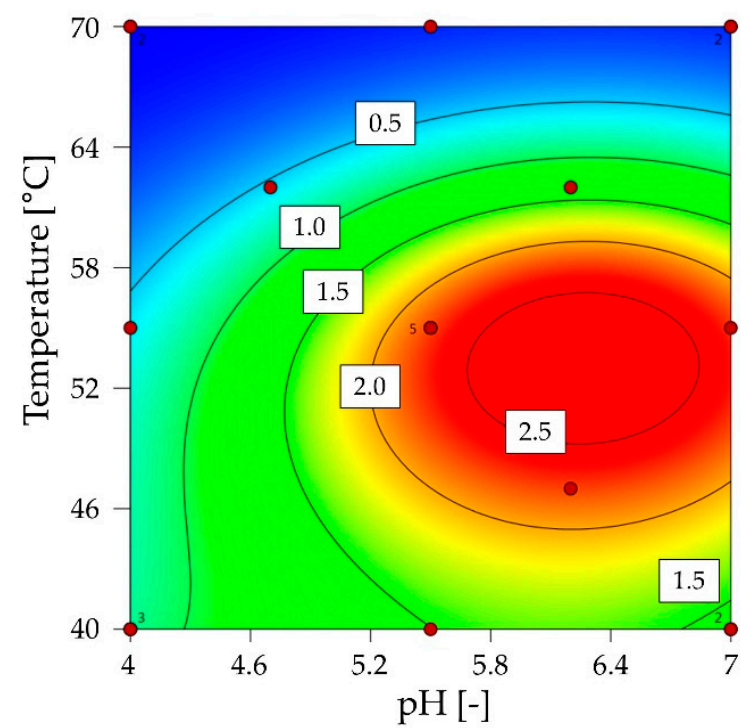

(a)

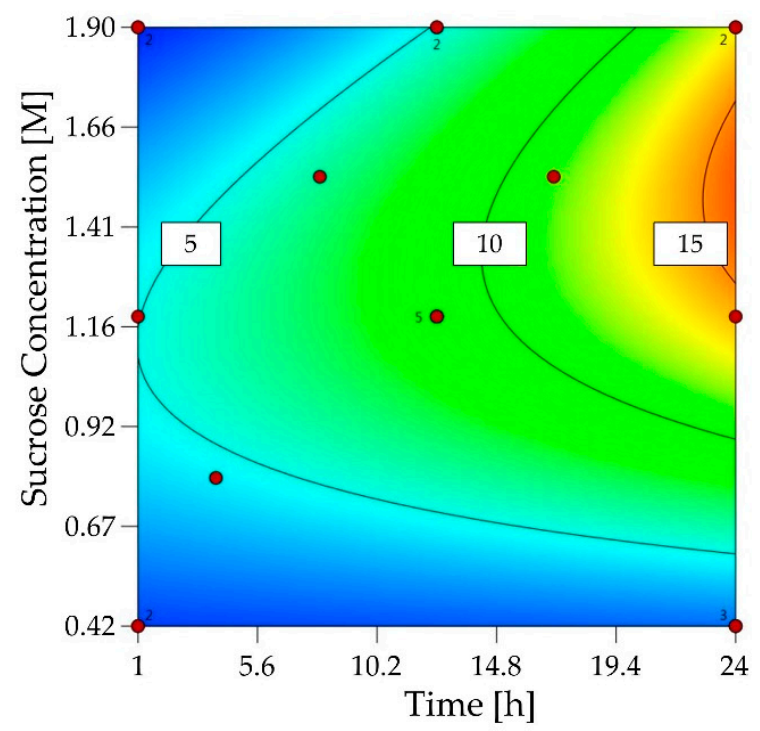

(b)

Figure 5. Contour plot of percentage FOS yield after catalysis with $\mathrm{G}^{6}$-FFT using a $5 \times$ concentrated supernatant solution. (a) FOS yield as a function of $\mathrm{pH}$ and temperature $(2 \mathrm{~h}$ reaction time, $1.63 \mathrm{M}$ sucrose). (b) FOS yield as a function of time and sucrose concentration ( $\mathrm{pH} 6.26,53{ }^{\circ} \mathrm{C}$ ).

The significant reduced quadratic model predicted higher FOS yields with increasing reaction time (Figure 5b). In contrast, the sucrose concentration caused a local maximum at 1.2-1.8 M. In this range, we anticipated FOS yields exceeding 15\%. Despite the significant lack of fit, an improved yield $(11.8 \pm 0.08 \%)$ was achieved after $24 \mathrm{~h}$ in the presence of $1.25 \mathrm{M}$ sucrose. This fits into the $95 \%$ confidence interval (7.2\%-23.9\%). Higher FOS yields with longer reaction times under mild conditions have been reported before, but the effect of sucrose concentrations on FOS yields were not considered in detail [36].

\subsubsection{Analysis of 6-SFT by-Product Formation}

The extracellular 6-SFT secreted by K. lactis has a dominant hydrolase activity, which is undesirable in a neoFOS production system because it favors the recovery of levan-type byproducts. We therefore characterized the enzyme as above in order to find conditions that limited its activity, using total activity $\left[\mathrm{U} \mathrm{mL}^{-1}\right]$ as the response and experimental ranges based on previous studies of fungal invertases 
and fructosyltransferases [38-41]. We selected the $\mathrm{pH}$ range $4-7$ and the temperature range $40-70{ }^{\circ} \mathrm{C}$ (Figure 6a). As before, an equivalent design was used to study the effect of sucrose concentration $(0.77-2.10 \mathrm{M})$ and reaction times of 1-24 h (Figure $6 \mathrm{~b}$ ).

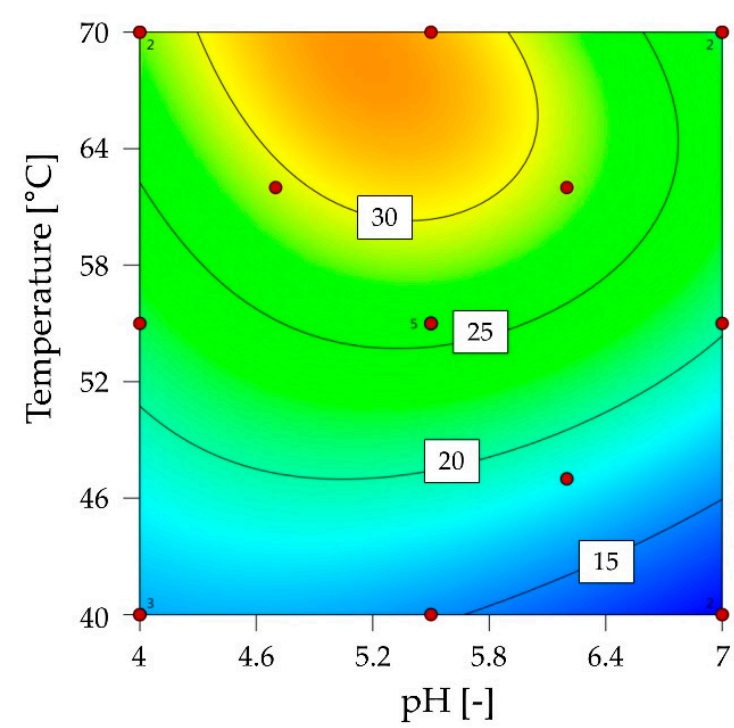

(a)

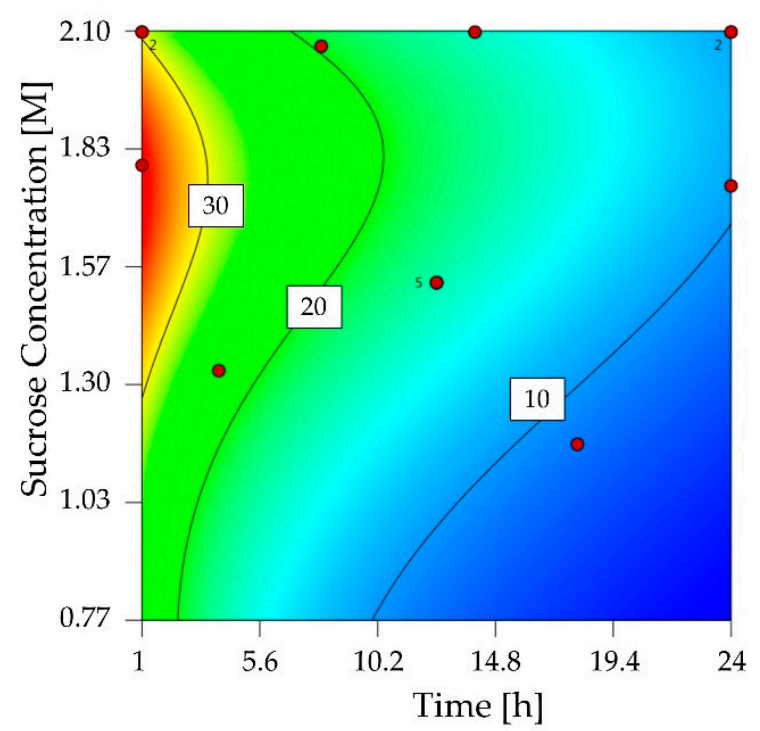

(b)

Figure 6. Contour plot of 6-SFT activity to determine the total activity [ $\left.\mathrm{U} \mathrm{mL}^{-1}\right]$ using a $3.2 \times$ concentrated supernatant solution. (a) Total activity [ $\mathrm{U} \mathrm{mL}^{-1}$ ] as a function of $\mathrm{pH}$ and temperature ( $2 \mathrm{~h}$ reaction time, $1.71 \mathrm{M}$ sucrose). (b) Total activity [ $\mathrm{U} \mathrm{mL}^{-1}$ ] as a function of time and sucrose concentration $\left(\mathrm{pH} 5.8,70{ }^{\circ} \mathrm{C}\right)$.

The significant reduced cubic model predicted maximum total activity within the limits of the experiment at $70{ }^{\circ} \mathrm{C}$ and $\mathrm{pH}$ 5.3. Confirmation runs $(\mathrm{n}=3)$ at $70{ }^{\circ} \mathrm{C}$ and $\mathrm{pH} 5.8$ revealed a total activity of $30.6 \pm 2.8 \mathrm{U} \mathrm{mL}^{-1}$. The $95 \%$ confidence interval was $27.2-34.6 \mathrm{U} \mathrm{mL}^{-1}$. The significant cubic model (Figure 6b) showed a broad high level of total activity with a reaction time of $1 \mathrm{~h}$ in the presence of 1.4-1.9 M sucrose. Although low total activity was predicted for all sucrose concentrations with a reaction time of $24 \mathrm{~h}$, this was strongly dependent on the sucrose concentration at $1 \mathrm{~h}$. Confirmation runs $(\mathrm{n}=3)$ lasting $2 \mathrm{~h}$ in the presence of $1.72 \mathrm{M}$ sucrose resulted in a total activity of $30.6 \pm 2.8 \mathrm{U} \mathrm{mL}^{-1}$. The $95 \%$ confidence interval was $28.7-42.2 \mathrm{U} \mathrm{mL}^{-1}$.

These findings can be exploited by adapting the reaction time and sucrose concentration to favor 1-FFT over 6-SFT activity, preventing the formation of levan-type byproducts and increasing the transferase/hydrolase ratio to boost FOS yields. Due to the low transferase/hydrolase ratio $(25.6 \pm 0.8 \%)$, both activities were attributed to $\beta$-D-fructofuranoside fructohydrolase. Extracellular inulinase (2,1- $\beta$-D-fructan fructanohydrolase, EC 3.2.1.7) [42] and invertase ( $\beta$-D-fructofuranoside fructohydrolase, EC 3.2.1.26) [43-45] have already been described in K. lactis, but an extracellular transferase activity has not been reported. However, invertases also catalyze the transfer of fructose units at high substrate concentrations [46-48], and the ability of fungal invertases to form 6-ketose as the main product of transferase activity has already been demonstrated [46].

\subsection{Immobilization of 1-FFT}

\subsubsection{Screening Immobilization Carriers and Conditions}

Having determined optimal reaction conditions favoring the activity of 1-FFT over 6-SFT, we next sought an appropriate carrier for enzyme immobilization in order to establish a two-step reaction process. We used 1-FFT as a model to screen different carriers because this enzyme is intrinsically more active than $\mathrm{G}^{6}$-FFT. For covalent immobilization, we used Immobead 150P polymethacrylate porous 
beads with epoxy functions (IP150), which were previously used to immobilize an acid phosphatase [49]. We also used the novel epoxy resin ECR8285 with a hydrophobic butyl methacrylate base, which has previously been used to immobilize a lipase [50]. For noncovalent ionic interactions, we used Mustang $\mathrm{Q}(\mathrm{PMQ})$ strong anion exchange membranes featuring quaternary amine ligands, which have been used for enzyme immobilization in earlier studies [34,51], as well as Mustang S (PMS) strong cation exchange membranes. Both membranes featured a hydrophobic polyethersulfone base. The treated carriers described above were compared to hydrophobic Sepabeads SP70 (Mitsubishi Chemical Corporation, Tokyo, Japan) and Amberlite XAD16N (DuPont de Nemours, Wilmington, USA) carriers, which have been used for the adsorption of amino acids and naringin [52,53].

The immobilization of 1-FFT by covalent binding to epoxy functional groups achieved the highest enzyme activity, with ECR8285 outperformig IP150 and producing a mean activity of $13.24 \pm 0.82 \mathrm{U}$ (Figure 7) at FOS yields of up to $60 \%$. The reversible immobilization of 1-FFT onto PMQ and PMS membranes by ionic interaction also achieved high activities of $9.74 \pm 0.47$ and $8.6 \pm 0.33 \mathrm{U}$, respectively. The better performance of covalent binding may reflect enzyme desorption from the PMQ/PMS membranes during the washing step after immobilization. Our results show that the ECR8285 carrier is preferable because it maximizes enzyme activity and enhances the yield of FOS. Covalent immobilization is preferred for industrial processes because enzymes retain their stability under harsh conditions [54], and accordingly, we predicted that immobilization on the ECR8285 carrier would prevent the loss of 1-FFT activity at reaction temperatures up to $70{ }^{\circ} \mathrm{C}$ and at $\mathrm{pH}$ extremes. We found that the immobilization of 1-FFT on the ECR8285 carrier at $\mathrm{pH} 9$ using sodium carbonate buffer led to an activity of $13.28 \pm 0.57 \mathrm{U}$, agreeing with previous reports that a higher $\mathrm{pH}$ can increase immobilization efficiency [38,55]. We also tested immobilization at $\mathrm{pH} 6$ because this is the $\mathrm{pH}$ of the fermentation process used to produce the enzyme. Immobilization at $\mathrm{pH} 6$ would allow the use of cell-free fermentation broth as the raw enzyme solution without buffer exchange. To increase the efficiency of immobilization at $\mathrm{pH} 6$, the ECR8285 surface was modified with either thiol or amine groups, the latter at $\mathrm{pH} 8.5$ or 10, as previously described [32]. The amine modification (at $\mathrm{pH} 8.5$ for $1 \mathrm{~h}$ at $25^{\circ} \mathrm{C}$ ) followed by immobilization at $\mathrm{pH} 6$ increased the maximum enzyme activity to $19.16 \pm 0.49 \mathrm{U}$. Our results therefore suggest that 1-FFT activity can be maximized by immobilization on an ECR8285 carrier at $\mathrm{pH} 6$ following the modification of that carrier with amine groups at $\mathrm{pH} 8.5$.

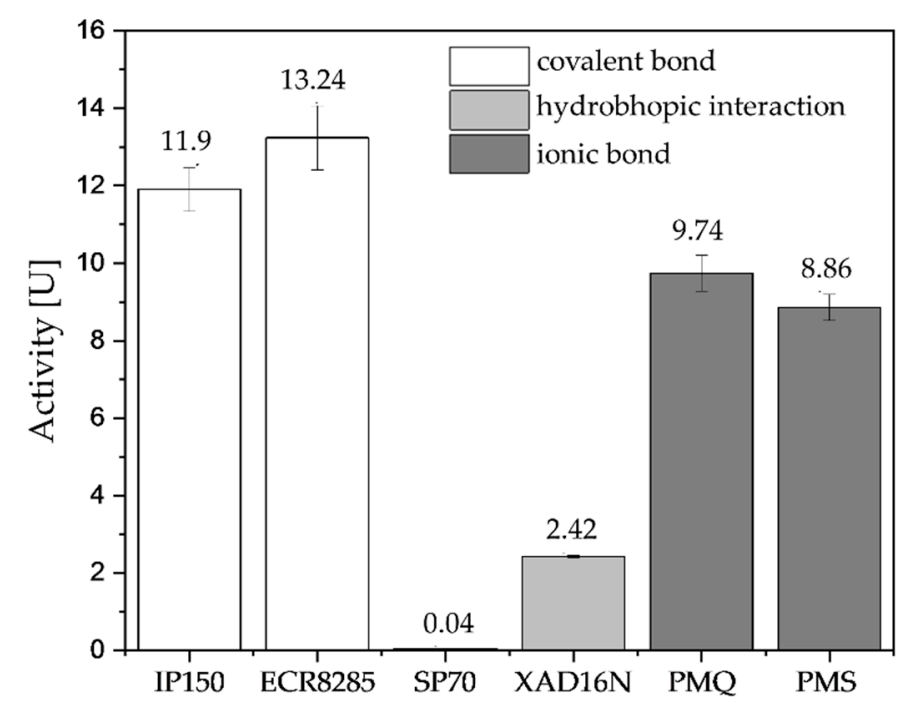

Figure 7. The effect of different carriers on 1-FFT activity. The 10-mL reactions were carried out for $48 \mathrm{~h}$ at $25^{\circ} \mathrm{C}$ in the presence of $0.2 \mathrm{~g}$ of each carrier. Activity [U] = amount of fructose transferred per minute using a standard catalysis protocol. 


\subsubsection{Optimization of 1-FFT Immobilization}

Having established the basic requirements for 1-FFT immobilization, we used a D-optimal experimental design to optimize the immobilization time and quantity of carrier. We initially set out to use both the efficiency of covalent binding and the enzyme activity after immobilization as responses. However, the difference of the protein concertation, indicating the total amount of immobilized protein on the carrier, could not be estimated and used as a response. The protein concentrations in the liquid phase of the approaches after the immobilization were below the detection limit of the Bradford and Pierce bicinchoninic acid protein assays. We therefore focused on the enzyme activity (Figure 8).

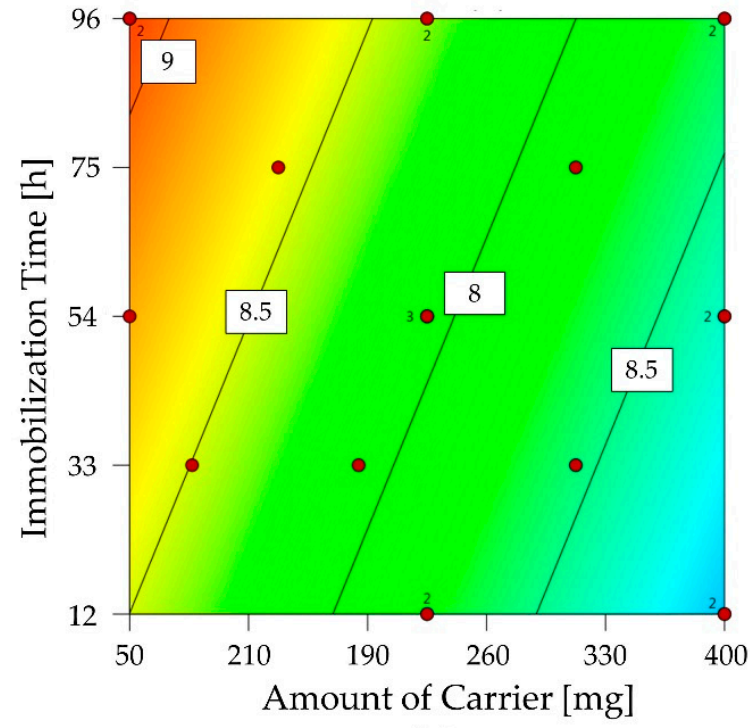

(a)

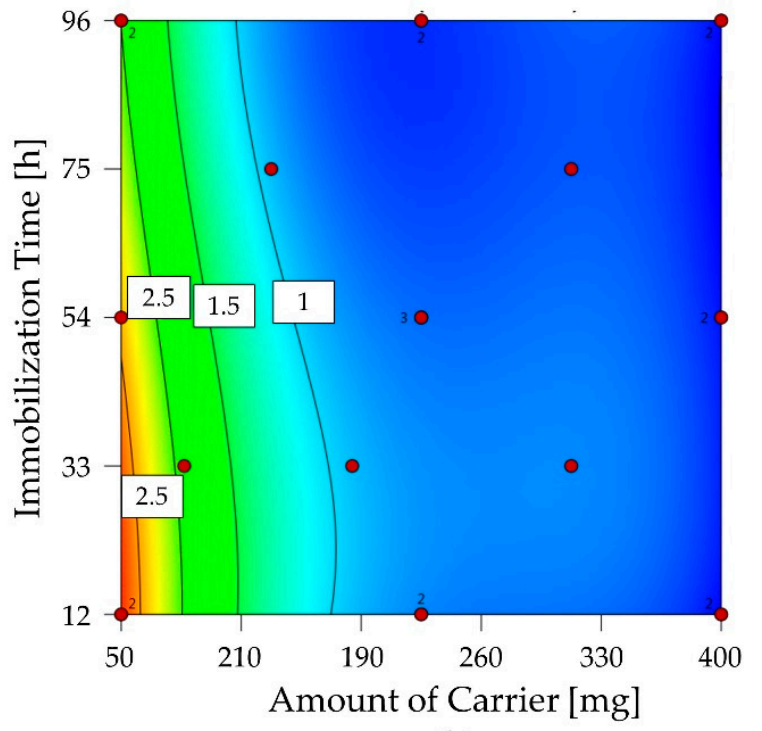

(b)

Figure 8. Contour plot for the optimization of immobilization based on the transfer activity [U] of (a) the carrier and (b) the supernatant.

The significant linear model of the carrier revealed maximum enzyme activity within the experimental range if the immobilization reaction lasted $96 \mathrm{~h}$ with $50 \mathrm{mg}$ of carrier. Confirmation runs under these conditions indicated activities of $10.66 \pm 0.05 \mathrm{U}$, thus exceeding the $95 \%$ confidence interval.

The significant cubic model of the supernatant revealed that enzyme activity was weakly influenced by the immobilization reaction time but strongly influenced by the amount of carrier, with higher amounts leading to negligible enzyme activity in the liquid phase of the immobilization reaction. As above, the activities in the confirmation run $(3.12 \pm 0.12 \mathrm{U})$ exceeded the $95 \%$ confidence interval (1.79-2.20 U). This may reflect differences in the protein composition of the crude enzyme solutions used for the initial model and the confirmation runs. To ensure a highly activated carrier is available for further experiments, enzymes were immobilized on $50 \mathrm{mg}$ of carrier within $96 \mathrm{~h}$.

\subsubsection{FOS Production with Free and Immobilized 1-FFT}

The previous step involved the immobilization of 1-FFT and the detection of its activity in immobilized form in a 1-mL reaction volume. If the reaction volume is increased to $100 \mathrm{~mL}$, the other reaction parameters (carrier quantity, stirrer speed and time) must be adapted accordingly. Only the sucrose concentration and reaction temperature remain the same. The results of the scale transfer experiments with free and immobilized 1-FFT are presented below (Figure 9).

These experiments confirmed that catalysis using immobilized 1-FFT is possible at the 100-mL scale, resulting in relative yields of $93.47 \pm 2.24 \%$ FOS. The reaction was scaled up to accommodate a two-step system and to evaluate whether it was necessary to incorporate glucose isomerase to remove glucose, which blocks the active site of the 1-FFT and thus inhibits FOS synthesis [21]. This effect 
was evident in our scaled-up experiment, where the sucrose concentration declines over time but the rate of FOS production also declines during the second hour of the reaction due to the increasing concentration of glucose (Figure 9).

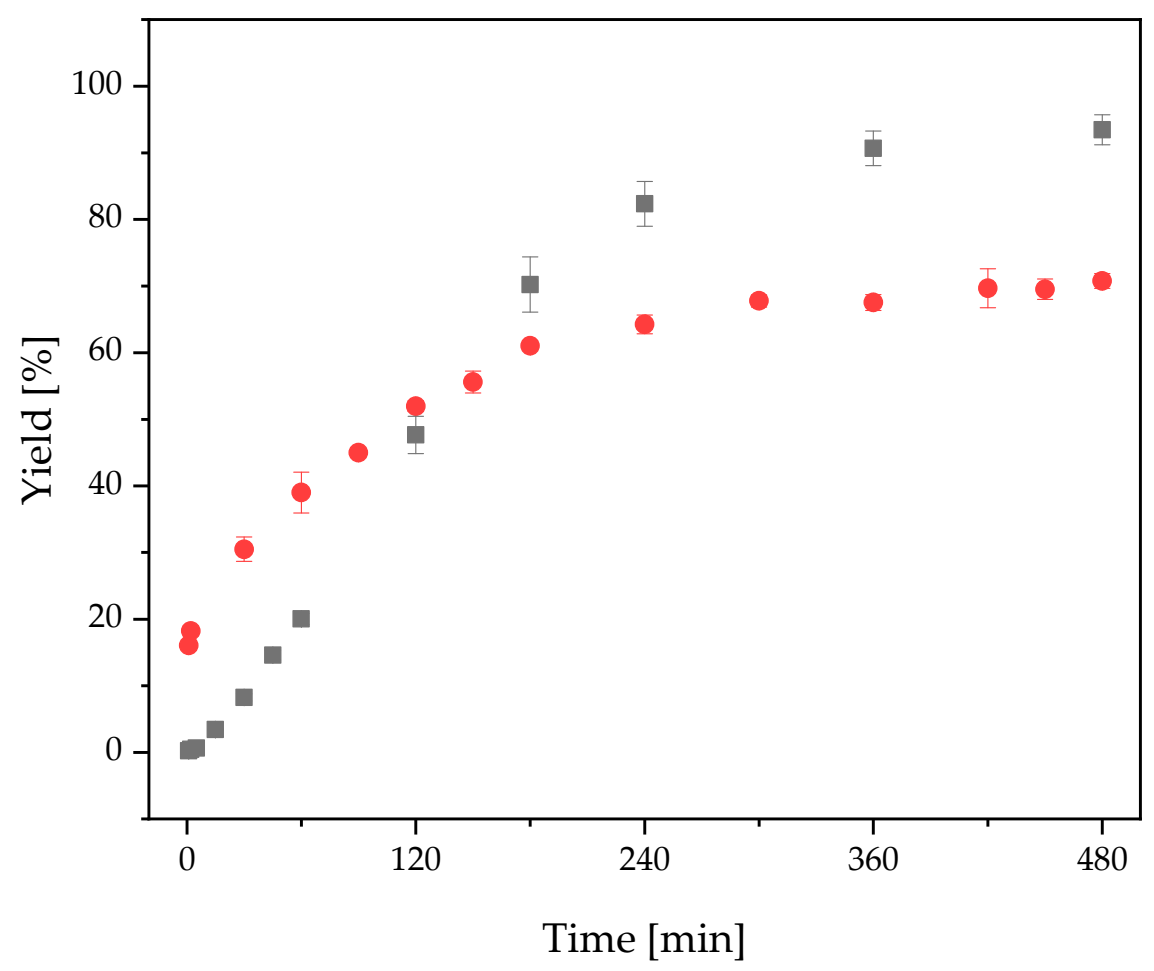

Figure 9. Time course of FOS relative yield by immobilized 1-FFT (black, $5 \mathrm{~g}$ loaded carrier) and 1-FFT crude enzyme solution (red, $10 \%(v / v))$.

\subsection{Two-Step Microscale neoFOS Production}

Although neokestose has been produced using various enzymes [56-60], we are unaware of any reports describing the production of high yields of elongated neoFOS $\left(>\mathrm{GF}_{3}\right)$ from sucrose. The extracellular $X$. dendrorhous fructosyltransferase showed high selectivity against the formation of neoFOS and a high transferase/hydrolase ratio, but the synthesis of $>\mathrm{GF}_{3}$ has not been achieved thus far. We therefore attempted the sequential synthesis of neoFOS using $\mathrm{G}^{6}$-FFT and 1-FFT according to a previously described model [19]. Initially, 1-mL scale reactions were carried out for $24 \mathrm{~h}$ shaking at $1000 \mathrm{rpm}$. The first step of the reaction using $\mathrm{G}^{6}$-FFT resulted in the production of neokestose, 1-kestose and possibly neonystose (Figure 10).

Following the first catalytic step, $100 \mu \mathrm{L}$ of the reaction volume was removed for analysis. The sucrose concentration was then increased to $2 \mathrm{M}$ by adding crystalline sucrose. After the second catalysis step, the degree of polymerization had increased to $\mathrm{GF}_{4}$, and two putative neoFOS products were detected. Because we used a two-step consecutive process, the slowest partial reaction determined the overall speed. The results indicated that neoFOS production could be increased by optimizing enzyme activity, which could be achieved by enzyme immobilization and/or expression under the control of a strong inducible promoter [11,35]. The use of 1-FFT for the first catalytic step did not achieve the clear initiation of the neoseries using already-elongated FOS in any of the consecutive second catalytic steps, probably reflecting the higher affinity of the enzymes for sucrose rather than inulin-type oligosaccharides. 


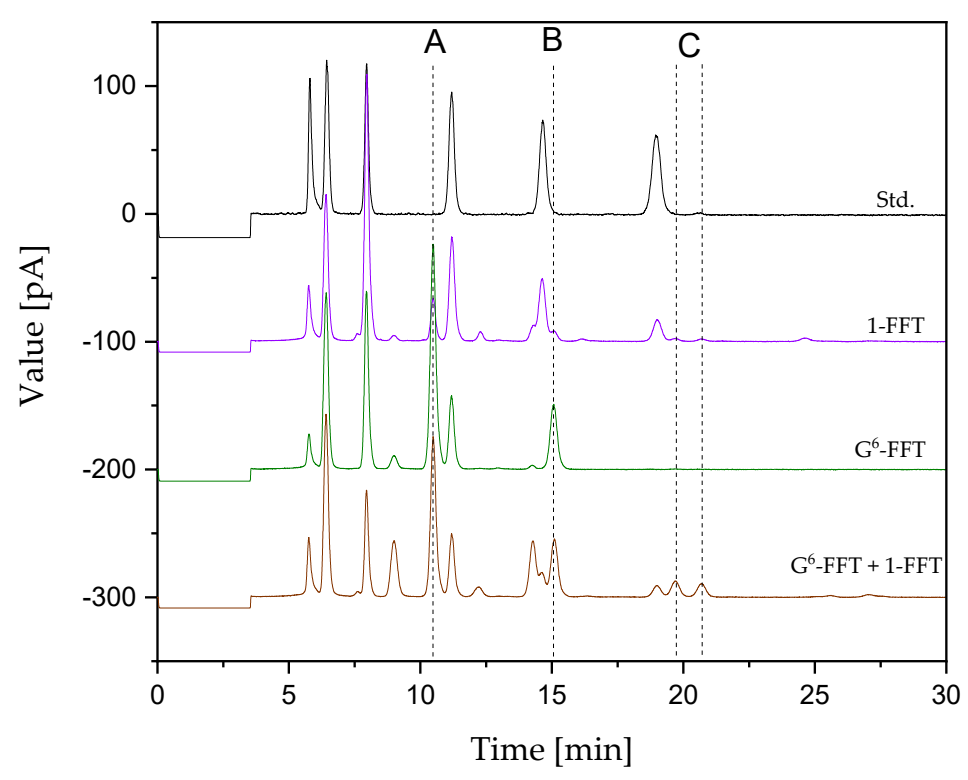

Figure 10. Chromatogram showing FOS standards and the two-step microscale production of neoFOS. Offset $=100 \mathrm{pA}$. The peaks correspond to $(\mathbf{A})$ neokestose, $(\mathbf{B})$ putative neonystose and $(\mathbf{C})$ putative neoFOS with four fructose units $\left(\mathrm{GF}_{4}\right)$.

\subsection{Two-Step 100-mL Scale neoFOS Production}

The two-step neoFOS production process described above was scaled up to a reaction volume of $100 \mathrm{~mL}$, and 1-FFT was immobilized on an ECR8285 carrier under the optimized conditions defined earlier. Although the $\mathrm{G}^{6}$-FFT was not immobilized, we used a $50 \times$ concentrated $\mathrm{G}^{6}$-FFT solution. These combined measures were applied to increase the yield of neoFOS and confirm the results from the microscale production process.

$\mathrm{G}^{6}$-FFT achieved the highest specificity for the neoseries. Given that the composition of the reaction solution in the first and the second steps differed mainly in the neoFOS concentration, the enlarged peak was assigned to the neoseries. Following the elution profile of FOS with different degrees of polymerization, this peak corresponds to a putative $\mathrm{GF}_{5}$ neoFOS species (Figure 11).

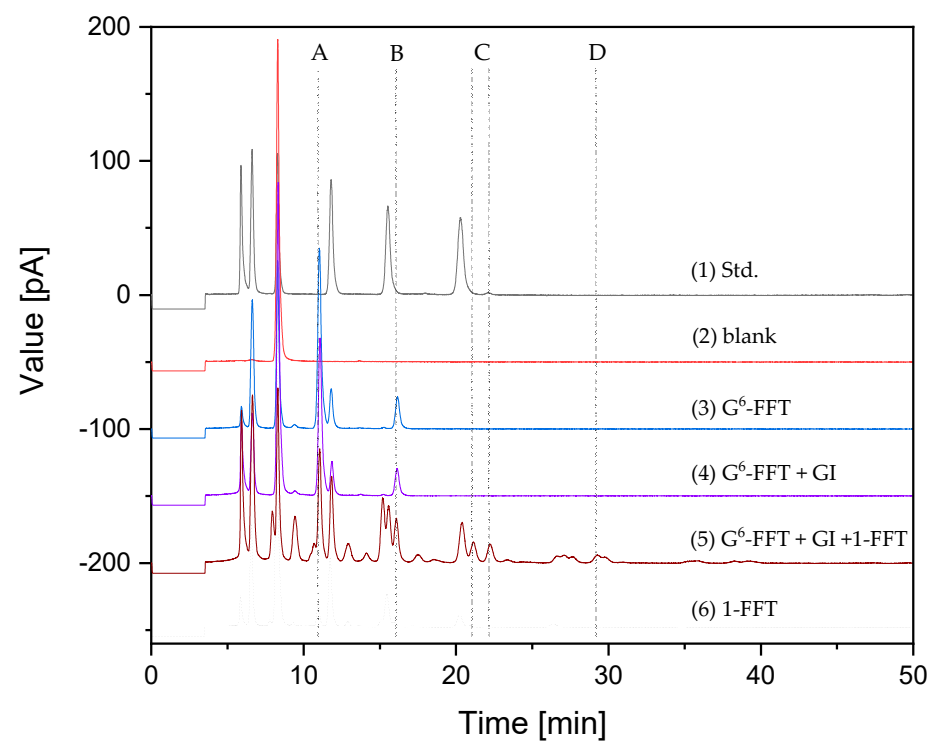

Figure 11. Chromatogram showing FOS standards and the two-step 100-mL scale production of neoFOS. Offset $=50 \mathrm{pA}$. The peaks correspond to $(\mathbf{A})$ neokestose, $(\mathbf{B})$ putative neonystose, $(\mathbf{C})$ putative neoFOS with four fructose units $\left(\mathrm{GF}_{4}\right)$, and $(\mathrm{D})$ putative neoFOS with five fructose five units $\left(\mathrm{GF}_{5}\right)$. 
The total yield of the two-step process was $47.02 \pm 3.02 \%$, which was determined with respect to the total available sucrose concentration (Table 1). The putative neo-GF 4 product reached a concentration of $20.8 \pm 1.91 \mathrm{mM}$. During the reaction, the distribution of products shifted toward FOS with higher degrees of polymerization.

Table 1. Substrate/product concentrations in a two-step neoFOS production process at the 100-mL scale showing each consecutive production step: (A) blank, (B) products of $\mathrm{G}^{6}$-FFT catalysis, (C) products of glucose isomerase, (D) concentrations following the addition of crystalline sucrose, and (E) products of 1-FFT catalysis.

\begin{tabular}{|c|c|c|c|c|c|}
\hline Process Step & $\begin{array}{c}\text { Sucrose } \\
\text { GF } \\
{[\mathrm{mM}]}\end{array}$ & $\begin{array}{c}\text { Glucose } \\
\text { G } \\
{[\mathrm{mM}]}\end{array}$ & $\begin{array}{c}\text { Neonystose } \\
\mathrm{GF}_{3} \\
{[\mathrm{mM}]}\end{array}$ & $\begin{array}{c}\text { Neoseries } \\
\mathrm{GF}_{4} \\
{[\mathrm{mM}]}\end{array}$ & $\mathrm{Y}_{\mathrm{FOS} \text {,total }}[\%]$ \\
\hline (A) Blank & $1849.80 \pm 113.89$ & $<\mathrm{LOD}$ & $<\mathrm{LOD}$ & $<$ LOD & - \\
\hline (B) $\mathrm{G}^{6}-\mathrm{FFT}$ & $501.56 \pm 42.41$ & $755.33 \pm 51.51$ & $33.05 \pm 3.01$ & $<\mathrm{LOD}$ & $68.55 \pm 4.11$ \\
\hline (C) GI & $529.94 \pm 23.64$ & $436.17 \pm 37.61$ & $32.51 \pm 0.49$ & $<\mathrm{LOD}$ & $68.69 \pm 2.93$ \\
\hline (D) Sucrose & $1916.78 \pm 136.67$ & $435.28 \pm 41.46$ & $30.04 \pm 4.47$ & $<\mathrm{LOD}$ & $31.08 \pm 1.88^{\dagger}$ \\
\hline (E) 1-FFT & $600.72 \pm 86.88$ & $1235.15 \pm 59.60$ & $53.07 \pm 1.66$ & $20.8 \pm 1.91$ & $47.02 \pm 3.02^{+}$ \\
\hline
\end{tabular}

The multiple peaks generated by 1-FFT when the reaction time was extended (Figure 11) were likely to be caused by the formation of FOS with different combinations of $\beta$-glycosidic bonds. These widely scattered byproducts of the inulin series did not allow the identification of potential neoFOS peaks. Furthermore, no commercial standards are available for short-chain neoFOS $\left(\mathrm{GF}_{2}-\mathrm{GF}_{6}\right)$, so it was not possible to send samples for external analysis. The availability of standards is essential for the qualitative and quantitative evaluation of neo-FOS production.

Hydrolase activity is undesirable during the production of FOS because this removes the sucrose substrate from the reaction. In K. lactis, the native invertase (6-SFT) has strong hydrolase activity against sucrose, thus reducing the amount of sucrose available to the heterologous 1-FFT. This could be addressed by isolating the 1-FFT from the crude enzyme preparation or using another expression system with lower hydrolytic activity.

\section{Materials and Methods}

\subsection{Microbial Strains, Reagents and Materials}

Kluyveromyces lactis strain GG799 was obtained from New England Biolabs (Frankfurt, Germany) and was used to express native 6-SFT and the integrated fructosyltransferase (1-FFT) gene from Aspergillus terreus NIH2624, which was described previously [11,12]. Xanthophyllomyces dendrorhous (DSM 5626) was obtained from the Leibniz Institute DSMZ German Collection of Microorganisms and Cell Cultures (Germany) and was used to express native $\mathrm{G}^{6}$-FFT. All chemical reagents, if not otherwise stated, were purchased from Merck (Darmstadt, Germany) and Carl Roth (Karlsruhe, Germany). For enzyme immobilization, a Lifetech ECR8285 sample was kindly provided by Purolite (Ratingen, Germany). Sepabeads SP70, Amberlite XAD16N and Immobead 150P carriers were obtained from Sigma-Aldrich Chemie (Taufkirchen, Germany). Mustang $Q$ and $S$ membranes were purchased from Pall (Dreieich, Germany). A FOS standard set comprising 1-kestose, nystose and $1^{\mathrm{F}}$-fructofranosylnystose was obtained from FUJIFILM Wako Pure Chemical Corporation (Osaka, Japan). Acetonitrile (certified ultra-high-performance liquid chromatography, UHPLC grade) was obtained from Thermo Fisher Scientific (Dreieich, Germany).

\subsection{Enzyme Production}

The A. terreus 1-FFT expressed in K. lactis was produced at the 5-L scale in a Lafors 3 fermenter (Infors, Bottmingen, Switzerland) using adapted FM22 medium for cultivation [61]. The K. lactis native 
6-SFT was produced at the 300-mL scale in a MiniBio 500 fermenter (Applikon Biotechnology, Delft, The Netherlands) using yeast extract dextrose medium containing $20 \mathrm{~g} \mathrm{~L}^{-1}$ casein peptone, $10 \mathrm{~g} \mathrm{~L}^{-1}$ yeast extract and $20 \mathrm{~g} \mathrm{~L}^{-1}$ glucose. The $X$. dendrorhous native $\mathrm{G}^{6}$-FFT was produced at the 5 -L scale in a Lafors 3 fermenter monitored using an ez-Control system (Applikon Biotechnology). The cells were cultivated in autoclaved yeast malt broth medium containing $5 \mathrm{~g} \mathrm{~L}^{-1}$ soy peptone, $3 \mathrm{~g} \mathrm{~L}^{-1}$ yeast extract, $3 \mathrm{~g} \mathrm{~L}^{-1}$ malt extract and $20 \mathrm{~g} \mathrm{~L}^{-1}$ sucrose.

The $\mathrm{pH}$ was maintained during fermentation by adding $25 \%(v / v)$ ammonia or (X. dendrorhous cultivations) $1 \mathrm{M}$ sodium hydroxide. We also added 0.02\% (v/v) Struktol J673A (Schill \& Seilacher, Hamburg, Germany) before fermentation began to avoid foaming. For K. lactis, the fermentation medium was maintained at $\mathrm{pH} 6.0,30^{\circ} \mathrm{C}$ and $>50 \%$ dissolved oxygen, the latter achieved with a stirrer speed of $1400 \mathrm{rpm}$ and a gassing rate of $1 \mathrm{VVM}$ air. For X. dendrorhous, the fermentation medium was maintained at $\mathrm{pH} 6.9$ and $20^{\circ} \mathrm{C}$, with the stirrer speed set to $500 \mathrm{rpm}$. The reactors were inoculated using cryostocks or precultures to optical densities of $\Delta \mathrm{OD}_{600}=0.1-0.2$ and were harvested during the stationary phase. The fermentation broth was centrifuged at $17,000 \times g$ to pellet insoluble components, and the supernatants were used directly as crude enzyme solutions because all three enzymes were secreted into the medium.

\subsection{Concentration of 6-SFT and G6-FFT Solutions}

To increase the specific activity of 6-SFT and $\mathrm{G}^{6}$-FFT, both enzyme solutions were concentrated in a 50-mL Amicon filtration cell fitted with a $30 \mathrm{kDa}$ polyethersulfone Biomax filter (Merck Millipore, Burlington, USA). The operating parameters were $150 \mathrm{rpm}$ and 1 bar overpressure at $8{ }^{\circ} \mathrm{C}$. An inert gas (nitrogen) was used to avoid chemical reactions. The double volume was flushed with $5 \mathrm{mM}$ potassium phosphate buffer ( $\mathrm{pH}$ 6.0), and then the volume was reduced and filter-sterilized to reach concentrations of 3.2-fold (6-SFT) and 5-fold ( $\left.\mathrm{G}^{6}-\mathrm{FFT}\right)$ the original. These retentates were used as enzyme concentrates to characterize the enzymes and for the two-step microscale production of neoFOS. For the two-step 100 -mL scale reaction, a new batch of $\mathrm{G}^{6}$-FFT was concentrated 50-fold using the same method.

\subsection{Enzyme Reactions}

Unless otherwise stated, $100 \mu \mathrm{L}$ of each crude enzyme solution was mixed with $900 \mu \mathrm{L}$ reaction buffer comprising $850 \mu \mathrm{L}$ sucrose solution $\left(600 \mathrm{~g} \mathrm{~L}^{-1}\right)$ premixed with $50 \mu \mathrm{L} 1 \mathrm{M}$ phosphate citrate buffer (pH 5.8). The reaction buffer was preheated to $70^{\circ} \mathrm{C}$ and, after adding the enzyme solution, the reaction was incubated at $70^{\circ} \mathrm{C}$ for $2 \mathrm{~h}$ shaking at $1000 \mathrm{rpm}$ in a Thermomixer (Eppendorf, Hamburg, Germany). The reaction was stopped by heating to $95{ }^{\circ} \mathrm{C}$ for $20 \mathrm{~min}$ in a heating block (Techne, Cambridge, United Kingdom). Enzyme activity was measured by UHPLC. One unit of total activity or hydrolase activity was defined as the amount of glucose $[\mu \mathrm{mol}]$, respectively, fructose $[\mu \mathrm{mol}]$ formed per unit time [min]. One unit of total transferase activity was defined as the amount of fructose [ $\mu \mathrm{mol}]$ used for the synthesis of FOS per unit time [min]. In the case of the volumetric activity, the activity is related to the used volume enzyme solution $\left[\mathrm{U} \mathrm{mL}^{-1}\right.$. The FOS yield [\%] was defined as the amount of FOS produced $[\mathrm{mM}]$ relative to the initial concentration of sucrose $[\mathrm{mM}]$ with respect to the added fructose units of each degree of polymerization. For the evaluation of enzyme immobilization, $50 \mathrm{mg}$ of loaded enzyme carrier was incubated with $1 \mathrm{~mL}$ reaction buffer (see above) for $2 \mathrm{~h}$, and the transferase activity was determined.

\subsection{Enzyme Immobilization}

Before and after each modification or immobilization step, the carrier was incubated with $10 \mathrm{~mL}$ of wash buffer ( $50 \mathrm{mM}$ potassium phosphate, $\mathrm{pH}$ 6) for $1 \mathrm{~h}$ on a rotary shaker. The spent buffer was then decanted and replaced with $10 \mathrm{~mL}$ of fresh wash buffer, and the carrier was incubated for a further $16 \mathrm{~h}$ on the shaker. The wash buffer was then discarded and the carrier was stored at $8{ }^{\circ} \mathrm{C}$. For enzyme immobilization, if not stated otherwise, $50 \mathrm{mg}$ of carrier was mixed with $7 \mathrm{~mL}$ of the enzyme solution and $3 \mathrm{~mL}$ of immobilization buffer $(50 \mathrm{mM}$ potassium phosphate, $\mathrm{pH}$ 6) in a 15-mL reaction vessel and 
incubated on a rotary shaker for $96 \mathrm{~h}$ at $8{ }^{\circ} \mathrm{C}$. The supernatant was then transferred to a fresh $15-\mathrm{mL}$ reaction vessel.

\subsection{Modification of Epoxy Carrier}

The epoxy groups on the surface of the IP150, ECR8285 and SP70 carriers were modified using thiol or amine solutions as previously described [25]. For the thiol modification, we prepared a mixture of $50 \mathrm{mM}$ sodium hydrogen carbonate ( $\mathrm{pH} 8.5$ ) and $1 \mathrm{mM}$ sodium sulfide. For each batch, $0.2 \mathrm{~g}$ of the carrier was incubated with $8 \mathrm{~mL}$ of the thiol solution in a 15-mL reaction vessel at $25^{\circ} \mathrm{C}$ for $2 \mathrm{~h}$. The modification solution was then removed. For the amine modification, $0.3 \mathrm{M}$ ethylenediamine (EDA) was adjusted to $\mathrm{pH} 8.5$ and $2 \mathrm{~mL}$ of this solution was mixed with $0.2 \mathrm{~g}$ of the carrier at $25^{\circ} \mathrm{C}$ for $2 \mathrm{~h}$. Approximately $20 \%$ of the epoxy groups are modified under these conditions [25]. For complete modification, the $\mathrm{pH}$ of the amine solution was increased to 10 and the reaction time extended to $16 \mathrm{~h}$ in parallel experiments. All preparations were then treated according to the washing protocol described above, prior to enzyme immobilization.

\subsection{Two-Step Microscale neoFOS Production}

Consecutive reaction steps were carried out in both directions with concentrated X. dendrorhous $\mathrm{G}^{6}$-FFT and A. terreus 1-FFT expressed in K. lactis. Each 1-mL reaction was carried out at a defined temperature and at $\mathrm{pH} 5.8$ for $24 \mathrm{~h}$. After the first step, crystalline sucrose was added to bring the concentration to $2 \mathrm{M}$ as determined by HPLC. Pure water was added along with the sucrose to ensure that the reaction volume was the same for each sample during the second step.

\subsection{Two-Step 100-mL Scale neoFOS Production}

Three 90-mL reaction batches were prepared comprising $1.8 \mathrm{M}$ sucrose in $50 \mathrm{mM}$ phosphate citrate buffer ( $\mathrm{pH}$ 6.2). Each batch was mixed with $10 \mathrm{~mL} 50 \times$ concentrated $\mathrm{G}^{6}$-FFT enzyme solution and incubated for $24 \mathrm{~h}$ at $53^{\circ} \mathrm{C}$, before heating to $95^{\circ} \mathrm{C}$ for $20 \mathrm{~min}$ to deactivate the enzyme. The $\mathrm{pH}$ was then adjusted to 7.6 by adding $2 \mathrm{M} \mathrm{NaOH}$ and $1 \mathrm{~g} \mathrm{~L}^{-1}$ of crystalline $\mathrm{MgSO}_{4} \cdot \mathrm{H}_{2} \mathrm{O}$ was added to induce the expression of glucose isomerase [24]. The reaction was incubated with $1 \mathrm{~g} \mathrm{~L}^{-1}$ glucose isomerase at $60{ }^{\circ} \mathrm{C}$ for $24 \mathrm{~h}$ to reduce the glucose concentration. In the second step, the $\mathrm{pH}$ was adjusted to 5.8 by adding crystalline citric acid and the sucrose concentration was increased to $2 \mathrm{M}$ by adding crystalline sucrose. For the second reaction step, the solutions were incubated at $70^{\circ} \mathrm{C}$ for $24 \mathrm{~h}$ with $5 \mathrm{~g} \mathrm{~L}^{-1}$ of the ECR8285 carrier loaded with 1-FFT (Figure 12.).

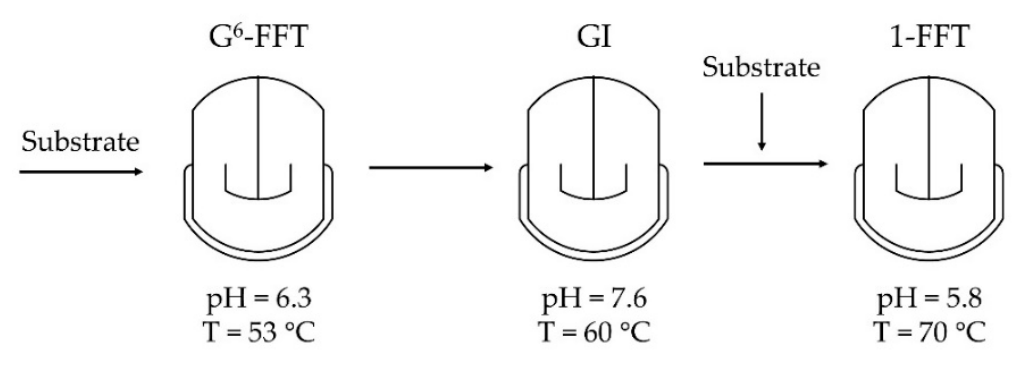

Figure 12. Process scheme of the 2-step neoFOS production in $100 \mathrm{~mL}$ scale.

\subsection{UHPLC Analytics}

UHPLC was carried out using an UltiMate 3000 system equipped with a Corona Veo RS Charged Aerosol Detector (Thermo Fisher Scientific, Dreieich, Germany). The analytes were separated using

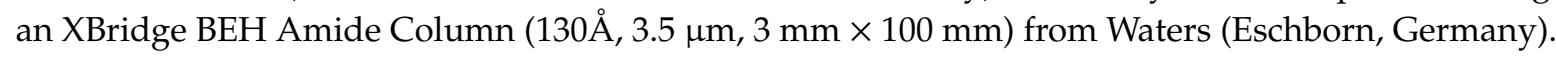
The solvent was $70 \%(v / v)$ acetonitrile (UHPLC grade) and $30 \%(v / v)$ water premixed with $0.2 \%(v / v)$ triethylamine. The flow rate was set to $1 \mathrm{~mL} \mathrm{~min}^{-1}$ with a running time of 36-50 min depending on the 
anticipated degree of polymerization among the products. Quantitative analysis was made possible by using a series of FOS standards FUJIFILM Wako Pure Chemical Corporation (Osaka, Japan). Samples were prepared by diluting 1:50 with a mixture of 50\% $(v / v)$ acetonitrile (LC-MS grade) and $50 \%(v / v)$ pure water.

\section{Conclusions}

We have successfully characterized three enzymes (A. terreus 1-FFT expressed in K. lactis, the native $K$. lactis 6-SFT and the native X. dendrorhous $\mathrm{G}^{6}$-FFT) and produced neoFOS as efficiently as possible by avoiding hydrolysis and the formation of levan-type FOS. The FOS yield is an important parameter which should be maximized to limit the abundance of sucrose or glucose/fructose hydrolysis products in the reaction, mainly because of their contribution to the glycemic index. The immobilization of 1-FFT was optimized to ensure high FOS yields with low quantities of carrier. The immobilized enzyme achieved higher yields than enzyme solutions in reactions lasting for $3 \mathrm{~h}$. Our results confirm that enzyme cascades involving two different fructosyltransferases can be used for the production of neoFOS with up to five added fructose units $\left(\mathrm{GF}_{5}\right)$. While this study focused on the immobilized 1-FFT, a utilization of a cascade reaction is possible, thus increasing the product value by an enhanced variety of different FOS types. The native X. dendrorhous $\mathrm{G}^{6}$-FFT represents the process bottleneck which requires improvement in further research. This can include research on efficient carrier immobilization and heterologous expression in a highly efficient production host, e.g., in Pichia pastoris [62]. This might result in a FOS distribution shift to neo-configurated $\mathrm{GF}_{4}$ and $\mathrm{GF}_{5}$ molecules, which can then be confirmed by NMR in a further process development.

Author Contributions: J.P.B. conceived and designed the experiments and wrote the paper. M.B. assisted with the experiments. D.G. and P.C. helped to draft and revise the manuscript and supervised the research. All authors contributed to manuscript revision, read and approved the submitted version.

Funding: This research was funded by the Hessen State Ministry of Higher Education, Research and the Arts within the Hessen initiative for scientific and economic excellence (LOEWE-Program).

Acknowledgments: The authors thank Richard M. Twyman for manuscript editing, as well as Miguel Alcalde Galeote and Francisco J. Plou (Institute of Catalysis and Petrochemistry, Spanish National Research Council, Spain) for the purified sample of 6-kestose.

Conflicts of Interest: The authors declare no conflict of interest.

\section{References}

1. Qiang, X.; YongLie, C.; QianBing, W. Health benefit application of functional oligosaccharides. Carbohydr. Polym. 2009, 77, 435-441. [CrossRef]

2. Charalampopoulos, D.; Rastall, R.A. Prebiotics in foods. Curr. Opin. Biotechnol. 2012, 23, 187-191. [CrossRef] [PubMed]

3. Torres, D.P.; Gonçalves, M.D.P.F.; Teixeira, J.A.; Rodrigues, L.R. Galacto-Oligosaccharides: Production, Properties, Applications, and Significance as Prebiotics. Compr. Rev. Food Sci. Food Saf. 2010, 9, 438-454. [CrossRef]

4. Roberfroid, M.B. Inulin-type fructans: Functional food ingredients. J. Nutr. 2007, 137, 2493S-2502S. [CrossRef] [PubMed]

5. Erdös, B.; Grachten, M.; Czermak, P.; Kovács, Z. Artificial Neural Network-Assisted Spectrophotometric Method for Monitoring Fructo-oligosaccharides Production. Food Bioprocess Technol. 2017, 11, 305-313. [CrossRef]

6. Spohner, S.C.; Schaum, V.; Quitmann, H.; Czermak, P. Kluyveromyces lactis: An emerging tool in biotechnology. J. Biotechnol. 2016, 222, 104-116. [CrossRef] [PubMed]

7. Kovács, Z.; Benjamins, E.; Grau, K.; Ur Rehman, A.; Ebrahimi, M.; Czermak, P. Recent developments in manufacturing oligosaccharides with prebiotic functions. Adv. Biochem. Eng. Biotechnol. 2014, 143, 257-295. [CrossRef] [PubMed] 
8. Rehman, A.U.; Kovacs, Z.; Quitmann, H.; Ebrahimi, M.; Czermak, P. Enzymatic production of fructo-oligosaccharides from inexpensive and abundant substrates using a membrane reactor system. Sep. Sci. Technol. 2016, 58, 548. [CrossRef]

9. Hidaka, H.; Eida, T.; Takizawa, T.; Tokunaga, T.; Tashiro, Y. Effects of Fructooligosaccharides on Intestinal Flora and Human Health. Bifidobact. Microflora 1986, 5, 37-50. [CrossRef]

10. Kilian, S.; Kritzinger, S.; Rycroft, C.; Gibson, G.; Du Preez, J. The effects of the novel bifidogenic trisaccharide, neokestose, on the human colonic microbiota. World J. Microbiol. Biotechnol. 2002, 18, 637-644. [CrossRef]

11. Spohner, S.C.; Czermak, P. Enzymatic production of prebiotic fructo-oligosteviol glycosides. J. Mol. Catal. B Enzym. 2016, 131, 79-84. [CrossRef]

12. Spohner, S.C.; Czermak, P. Heterologous expression of Aspergillus terreus fructosyltransferase in Kluyveromyces lactis. New Biotechnol. 2016, 33, 473-479. [CrossRef] [PubMed]

13. Yun, J.W. Fructooligosaccharides-Occurrence, preparation, and application. Enzym. Microb. Technol. 1996, 19, 107-117. [CrossRef]

14. Hidaka, H.; Hirayama, M.; Yamada, K. Review Article: Fructooligosaccharides Enzymatic Preparation and Biofunctions. J. Carbohydr. Chem. 1991, 10, 509-522. [CrossRef]

15. Simmering, R.; Blaut, M. Pro- and prebiotics-The tasty guardian angels? Appl. Microbiol. Biotechnol. 2001, 55, 19-28. [CrossRef]

16. Lim, J.S.; Lee, J.H.; Kang, S.W.; Park, S.W.; Kim, S.W. Studies on production and physical properties of neo-FOS produced by co-immobilized Penicillium citrinum and neo-fructosyltransferase. Eur. Food Res. Technol. 2007, 225, 457-462. [CrossRef]

17. Hidalgo-Cantabrana, C.; Delgado, S.; Ruiz, L.; Ruas-Madiedo, P.; Sánchez, B.; Margolles, A. Bifidobacteria and Their Health-Promoting Effects. Microbiol. Spectr. 2017, 5, 73-98. [CrossRef]

18. Gibson, G.; Wang, X. Regulatory effects of bifidobacteria on the growth of other colonic bacteria. J. Appl. Bacteriol. 1994, 77, 412-420. [CrossRef]

19. Linde, D.; Rodríguez-Colinas, B.; Estévez, M.; Poveda, A.; Plou, F.J.; Lobato, M.F. Analysis of neofructooligosaccharides production mediated by the extracellular $\beta$-fructofuranosidase from Xanthophyllomyces dendrorhous. Bioresour. Technol. 2012, 109, 123-130. [CrossRef]

20. Cruz, R.; Cruz, V.D.; Belini, M.Z.; Belote, J.G.; Vieira, C.R. Production of fructooligosaccharides by the mycelia of Aspergillus japonicus immobilized in calcium alginate. Bioresour. Technol. 1998, 65, 139-143. [CrossRef]

21. Chuankhayan, P.; Hsieh, C.-Y.; Huang, Y.-C.; Hsieh, Y.-Y.; Guan, H.-H.; Hsieh, Y.-C.; Tien, Y.-C.; Chen, C.-D.; Chiang, C.-M.; Chen, C.-J. Crystal Structures of Aspergillus japonicus Fructosyltransferase Complex with Donor/Acceptor Substrates Reveal Complete Subsites in the Active Site for Catalysis. J. Boil. Chem. 2010, 285, 23251-23264. [CrossRef] [PubMed]

22. Ashby, R.; Hjortkjaer, R.; Stavnsbjerg, M.; Gürtler, H.; Pedersen, P.; Bootman, J.; Hudson-Walker, G.; Tesh, J.; Willoughby, C.; West, H.; et al. Safety evaluation of Streptomyces murinus glucose isomerase. Toxicol. Lett. 1987, 36, 23-35. [CrossRef]

23. Skoet, G.; Guertler, H. Xylose Isomerase (Glucose Isomerase) from Streptomyces Murinus Cluster. U.S. Patent US4687742A, 18 August 1987.

24. Jørgensen, O.B.; Karlsen, L.G.; Nielsen, N.B.; Pedersen, S.; Rugh, S. A New Immobilized Glucose Isomerase with High Productivity Produced by a Strain ofStreptomyces murinus. Starch Stärke 1988, 40, 307-313. [CrossRef]

25. Mohamad, N.R.; Marzuki, N.H.C.; Buang, N.A.; Huyop, F.; Wahab, R.A. An overview of technologies for immobilization of enzymes and surface analysis techniques for immobilized enzymes. Biotechnol. Biotechnol. Equip. 2015, 29, 205-220. [CrossRef] [PubMed]

26. DiCosimo, R.; McAuliffe, J.; Poulose, A.J.; Bohlmann, G. Industrial use of immobilized enzymes. Chem. Soc. Rev. 2013, 42, 6437. [CrossRef] [PubMed]

27. De Carvalho, C.C. Enzymatic and whole cell catalysis: Finding new strategies for old processes. Biotechnol. Adv. 2011, 29, 75-83. [CrossRef] [PubMed]

28. Sheldon, R.A.; van Pelt, S. Enzyme immobilisation in biocatalysis: Why, what and how. Chem. Soc. Rev. 2013, 42, 6223-6235. [CrossRef]

29. Lorenzoni, A.S.; Aydos, L.F.; Klein, M.P.; Rodrigues, R.C.; Hertz, P.F. Fructooligosaccharides synthesis by highly stable immobilized $\beta$-fructofuranosidase from Aspergillus aculeatus. Carbohydr. Polym. 2014, 103, 193-197. [CrossRef] 
30. Tufvesson, P.; Lima-Ramos, J.; Nordblad, M.; Woodley, J.M. Guidelines and Cost Analysis for Catalyst Production in Biocatalytic Processes. Org. Process. Res. Dev. 2011, 15, 266-274. [CrossRef]

31. Nelson, J.M.; Griffin, E.G. Adsorption of Invertase. J. Am. Chem. Soc. 1916, 38, 1109-1115. [CrossRef]

32. Mateo, C.; Grazu, V.; Pessela, B.; Montes, T.; Palomo, J.; Torres, R.T.R.; Gallego, F.L.; Fernandez-Lafuente, R.; Guisan, J. Advances in the design of new epoxy supports for enzyme immobilization-stabilization. Biochem. Soc. Trans. 2007, 35, 1593-1601. [CrossRef] [PubMed]

33. Mateo, C.; Grazu, V.; Palomo, J.M.; López-Gallego, F.; Fernandez-Lafuente, R.; Guisan, J.M. Immobilization of enzymes on heterofunctional epoxy supports. Nat. Protoc. 2007, 2, 1022-1033. [CrossRef] [PubMed]

34. Engel, L.; Ebrahimi, M.; Czermak, P. Membrane chromatography reactor system for the continuous synthesis of galactosyl-oligosaccharides. Desalination 2008, 224, 46-51. [CrossRef]

35. Míguez, N.; Gimeno-Pérez, M.; Fernández-Polo, D.; Cervantes, F.V.; Ballesteros, A.O.; Fernández-Lobato, M.; Ribeiro, M.H.; Plou, F.J. Immobilization of the $\beta$-fructofuranosidase from Xanthophyllomyces dendrorhous by Entrapment in Polyvinyl Alcohol and Its Application to Neo-Fructooligosaccharides Production. Catalysts 2018, 8, 201. [CrossRef]

36. Linde, D.; Macias, I.; Fernández-Arrojo, L.; Plou, F.J.; Jiménez, A.; Fernández-Lobato, M. Molecular and biochemical characterization of a beta-fructofuranosidase from Xanthophyllomyces dendrorhous. Appl. Environ. Microbiol. 2009, 75, 1065-1073. [CrossRef] [PubMed]

37. Ning, Y.; Wang, J.; Chen, J.; Yang, N.; Jin, Z.; Xu, X. Production of neo-fructooligosaccharides using free-whole-cell biotransformation by Xanthophyllomyces dendrorhous. Bioresour. Technol. 2010, 101, 7472-7478. [CrossRef] [PubMed]

38. Ghazi, I.; De Segura, A.G.; Fernández-Arrojo, L.; Alcalde, M.; Yates, M.; Rojas-Cervantes, M.L.; Plou, F.J.; Ballesteros, A. Immobilisation of fructosyltransferase from Aspergillus aculeatus on epoxy-activated Sepabeads EC for the synthesis of fructo-oligosaccharides. J. Mol. Catal. B Enzym. 2005, 35, 19-27. [CrossRef]

39. Hirayama, M.; Sumi, N.; Hidaka, H. Purification and Properties of a Fructooligosaccharide-producing $\beta$-Fructofuranosidase from Aspergillus niger ATCC 20611. Agric. Boil. Chem. 1989, 53, 667-673. [CrossRef]

40. Kushi, R.T.; Monti, R.; Contiero, J. Production, purification and characterization of an extracellular inulinase from Kluyveromyces marxianus var. bulgaricus. J. Ind. Microbiol. Biotechnol. 2000, 25, 63-69. [CrossRef]

41. Guo, W.; Yang, H.; Qiang, S.; Fan, Y.; Shen, W.; Chen, X. Overproduction, purification, and property analysis of an extracellular recombinant fructosyltransferase. Eur. Food Res. Technol. 2016, 242, 1159-1168. [CrossRef]

42. Cruz-Guerrero, A.E.; Olvera, J.L.; García-Garibay, M.; Gómez-Ruiz, L. Inulinase-hyperproducing strains of Kluyveromyces sp. isolated from aguamiel (Agave sap) and pulque. World J. Microbiol. Biotechnol. 2006, 22, 115-117. [CrossRef]

43. Dworschack, R.G.; Wickerham, L.J. Production of Extracellular and Total Invertase by Candida utilis, Saccharomyces cerevisiae, and Other Yeasts. Appl. Microbiol. 1961, 9, 291-294. [PubMed]

44. Rouwenhorst, R.J.; Visser, L.E.; Van Der Baan, A.A.; Scheffers, W.A.; Van Dijken, J.P. Production, Distribution, and Kinetic Properties of Inulinase in Continuous Cultures of Kluyveromyces marxianus CBS 6556. Appl. Environ. Microbiol. 1988, 54, 1131-1137. [PubMed]

45. Rouwenhorst, R.J.; Ritmeester, W.S.; Scheffers, W.A.; Van Dijken, J.P. Localization of inulinase and invertase in Kluyveromyces species. Appl. Environ. Microbiol. 1990, 56, 3329-3336. [PubMed]

46. Álvaro-Benito, M.; De Abreu, M.; Fernández-Arrojo, L.; Plou, F.J.; Jiménez-Barbero, J.; Ballesteros, A.; Polaina, J.; Fernández-Lobato, M. Characterization of a $\beta$-fructofuranosidase from Schwanniomyces occidentalis with transfructosylating activity yielding the prebiotic 6-kestose. J. Biotechnol. 2007, 132, 75-81. [CrossRef] [PubMed]

47. Farine, S.; Versluis, C.; Bonnici, P.; Heck, A.; L'Hommé, C.; Puigserver, A.; Biagini, A. Application of high performance anion exchange chromatography to study invertase-catalysed hydrolysis of sucrose and formation of intermediate fructan products. Appl. Microbiol. Biotechnol. 2001, 55, 55-60. [CrossRef] [PubMed]

48. Lincoln, L.; More, S.S. Bacterial invertases: Occurrence, production, biochemical characterization, and significance of transfructosylation. J. Basic Microbiol. 2017, 57, 803-813. [CrossRef] [PubMed]

49. Babich, L.; Hartog, A.F.; Van Der Horst, M.A.; Wever, R. Continuous-Flow Reactor-Based Enzymatic Synthesis of Phosphorylated Compounds on a Large Scale. Chem. Eur. J. 2012, 18, 6604-6609. [CrossRef] [PubMed] 
50. Li, X.; Li, D.; Wang, W.; Durrani, R.; Yang, B.; Wang, Y. Immobilization of SMG1-F278N lipase onto a novel epoxy resin: Characterization and its application in synthesis of partial glycerides. J. Mol. Catal. B Enzym. 2016, 133, 154-160. [CrossRef]

51. Weaver, J.; Husson, S.M.; Murphy, L.; Wickramasinghe, S.R. Anion exchange membrane adsorbers for flow-through polishing steps: Part II. Virus, host cell protein, DNA clearance, and antibody recovery. Biotechnol. Bioeng. 2013, 110, 500-510. [CrossRef]

52. Cruz, I.B.; Jorge, R.F.; Castro, P.M.L.; Ferraro, V.; Pintado, M.M. Effects of Physical Parameters onto Adsorption of the Borderline Amino Acids Glycine, Lysine, Taurine, and Tryptophan upon Amberlite XAD16 Resin. J. Chem. Eng. Data 2013, 58, 707-717.

53. Ghanem, F. Juice Debittering: Basic Science, Optimization, and Recent Advances. In Proceedings of the ASME 2012 Citrus Engineering Conference, Lake Alfred, FL, USA, 15 March 2012; p. 1, ISBN 978-0-7918-9998-4.

54. Zhang, Y.-W.; Tiwari, M.K.; Jeya, M.; Lee, J.-K. Covalent immobilization of recombinant Rhizobium etli CFN42 xylitol dehydrogenase onto modified silica nanoparticles. Appl. Microbiol. Biotechnol. 2011, 90, 499-507. [CrossRef]

55. Sun, J.; Chen, Y.; Sheng, J.; Sun, M. Immobilization of Yarrowia lipolytica Lipase on Macroporous Resin Using Different Methods: Characterization of the Biocatalysts in Hydrolysis Reaction. BioMed Res. Int. 2015, 2015, 1-7.

56. Gross, D.; Blanchard, P.H.; Bell, D.J. neoKestose: A trisaccharide formed from sucrose by yeast invertase. J. Chem. Soc. 1954, 1727-1730. [CrossRef]

57. Gutiérrez-Alonso, P.; Fernández-Arrojo, L.; Plou, F.J.; Fernández-Lobato, M. Biochemical characterization of a $\beta$-fructofuranosidase fromRhodotorula dairenensiswith transfructosylating activity. FEMS Yeast Res. 2009, 9, 768-773. [CrossRef]

58. Grizard, D.; Barthomeuf, C. Enzymatic synthesis and structure determination of NEO-FOS. Food Biotechnol. 1999, 13, 93-105. [CrossRef]

59. Chen, J.; Chen, X.; Xu, X.; Ning, Y.; Jin, Z.; Tian, Y. Biochemical characterization of an intracellular 6G-fructofuranosidase from Xanthophyllomyces dendrorhous and its use in production of neo-fructooligosaccharides (neo-FOSs). Bioresour. Technol. 2011, 102, 1715-1721. [CrossRef]

60. Sheu, D.-C.; Chang, J.-Y.; Chen, Y.-J.; Lee, C.-W. Production of high-purity neofructooligosaccharides by culture of Xanthophyllomyces dendrorhous. Bioresour. Technol. 2013, 132, 432-435. [CrossRef]

61. Burghardt, J.P.; Oestreich, A.M.; Weidner, T.; Gerlach, D.; Czermak, P. Development of a Chemically Defined Fermentation Medium for the Production of a New Recombinant Fructosyltransferase. Int. J. Pharma Med. Biol. Sci. 2018, 7. [CrossRef]

62. Gimeno-Pérez, M.; Linde, D.; Fernández-Arrojo, L.; Plou, F.J.; Fernández-Lobato, M. Heterologous overproduction of $\beta$-fructofuranosidase from yeast Xanthophyllomyces dendrorhous, an enzyme producing prebiotic sugars. Appl. Microbiol. Biotechnol. 2015, 99, 3459-3467. [CrossRef] 